\title{
"Blue" photonics: optics in the sea
}

\author{
J. Watson \\ School of Engineering, University of Aberdeen, Aberdeen, AB24 3UE, Scotland \\ @abdn.ac.uk \\ W. Jueptner \\ w.jueptner@abdn.ac.uk \\ School of Engineering, University of Aberdeen, Aberdeen, AB24 3UE, Scotland
}

The oceans and coastal zones of the world are vitally important resources for many aspects of human life. Their exploitation as sources of food dates back to the beginnings of civilisation, but in relatively more recent times, by comparison, our oceans have become valuable sources of energy. The oil and gas industries are well known examples of how the oceans can be exploited to provide us with our fossil fuel needs. More recently, wind, tidal and wave power are coming to the fore as we look more towards renewable sources of energy. We should also not forget the extraction of other mineral resources. However, the gathering and farming of food is still the most significant treasure that the oceans hold for us; and its control, management and sustainability are vital aspects of sea utilisation. There are many significant challenges which still face us in our drive to understand and utilise this unique environment and to exploit the natural resources contained within it. New techniques and instruments are continually being developed to help us explore and enhance our appreciation of the sea and how we depend upon it. Foremost amongst these is the increased use of optical techniques or photonics that help to us to extract information about the nature of the oceans, its constituents and its behaviour.

In this special issue of the Journal of the European Optical Society we focus on what we term "Blue" Photonics: in other words, the use and understanding of optics in the sea (and also in rivers and lakes). Such a title embraces a wide range of aspects of optics and light in the oceans from basic optical propagation through water to the design of complex instruments which enable us to measure its properties and behaviour. The chosen papers highlight major topics in photonics applied to marine science and engineering from fundamental science through marine optics, optical metrology, biological optics, environmental optics to technology and instrumentation.

A number of papers are related to the measurement of ocean water properties like the transparency measurements using the Secchi Disc[1] or the colour evaluation with the Forel-Ule comparator [2] and its change as a function of time [3] caused by pollution or the presence of micro-organism. Another two papers deal with the development of new measurement methods and their influencing parameters. An interesting method in this area is the measurement of reflectance scattering with the application to the measurement of waves on the ocean surface [4] as well as to the determination of solutes in the water.
A complementary method is the measurement of light fluctuations in different depths under the surface giving an excellent approach to the wave evaluation [5]. The detection of microbubbles in the subsea environment is discussed by Zielinski et al [6]. A new measurement method too is the Laser Line Scan method in the CW mode as well as in pulsed mode [7]. This method increases the resolution and is robust against environmental influences and scans a larger volume. Imaging methods are another area of underwater metrology systems. Systems like the LOKI system [8] are used to image Plankton.

The papers here act only as a primer for the vast amount of work now being undertaken in Blue Photonics and we hope that they will serve as a catalyst for increased use of optics in the sea.

\section{References}

[1] M. R. Wernand, "On the history of the Secchi disc" J. Europ. Opt. Soc. Rap. Public. 5, 10013S (2010).

[2] M. R. Wernand, and H. J. van der Woerd, "Spectral analyses of the Forel-Ule ocean colour comparator scale" J. Europ. Opt. Soc. Rap. Public. 5, 10014S (2010).

[3] M. R. Wernand, and H. J. van der Woerd, "Ocean colour changes in the North Pacific since 1930" J. Europ. Opt. Soc. Rap. Public. 5, 10015s (2010).

[4] D. Creanor, and A. Cunningham, "Origins of ambiguity in the inversion of remote sensing reflectance signals by spectral matching in optically complex shelf seas" J. Europ. 0pt. Soc. Rap. Public. 5, 10018s (2010).

[5] M. Hieronymi, and A. Macke, "Spatiotemporal underwater light field fluctuations in the open ocean" J. Europ. Opt. Soc. Rap. Public. 5, 10019S (2010).

[6] 0. Zielinski, B. Saworski, and J. Schulz, "Marine bubble detection using optical-flow techniques" J. Europ. Opt. Soc. Rap. Public. 5, 10016s (2010).

[7] F. M. Caimi, and F. R. Dalgleish, "Performance considerations for continuous-wave and pulsed laser line scan (LLS) imaging systems" J. Europ. Opt. Soc. Rap. Public. 5, 10020s (2010).

[8] J. Schulz, K. Barz, P. Ayon, A. Lüdtke, 0. Zielinski, D. Mengedoht, and H.-J. Hirche, "Imaging of plankton specimens with the lightframe on-sight keyspecies investigation (LOKI) system" J. Europ. Opt. Soc. Rap. Public. 5, $10017 \mathrm{~s}$ (2010). 